\title{
SIGN OF THE ELECTRIC FIELD GRADIENT TENSOR AND THE NATURE OF THE LOW TEMPERATURE PHASE TRANSITION IN Fe(PYRIDINE) ${ }_{2} \mathrm{Cl}_{2}$
}

\author{
W.M. REIFF \\ Department of Chemistry, Northeastern University, Boston, Massachusetts 02115, USA \\ R.B. FRANKEL \\ Francis Bitter National Magnet Laboratory, Massachusetts Institute of Technology, \\ Cambridge, Massachusetts 02139, USA \\ and \\ B.F, LITTLE and Gary J. LONG* \\ Department of Chemistry, University of Missouri-Rolla, Rolla, Missouri 65401, USA
}

\begin{abstract}
Mössbuuer spectra of $\mathrm{Fe}(\text { pyridine })_{2} \mathrm{Cl}_{2}$ have been determined in large external magnetic fields at room temperature and $78 \mathrm{~K}$. The principal component of the electric field gradient tensor is positive and consistent with an electron in the $\mathrm{d}_{x y}$ urbital. The results indicate no change in orbital ground state for the low temperature phase transition of this material.
\end{abstract}

The chloro-bridged polymeric octahedral complex bis(pyridine)dichloroiron(II), $\mathrm{Fe}(\mathrm{py})_{2} \mathrm{Cl}_{2}$, has been the subject of several recent investigations. A detailed study of this complex by Long et al. [1] demonstrated that it contains high-spin iron(II) with an indication of ferromagnetic behavior at low temperature. This study also revealed that $\mathrm{Fe}(\mathrm{py})_{2} \mathrm{Cl}_{2}$, when prepared by vacuum thermolysis of $\mathrm{Fe}(\mathrm{py})_{4} \mathrm{Cl}_{2}$, exhibited a four line Mössbauer spectrum at intermediate temperatures ( 195 and $78 \mathrm{~K}$ ), which is indicative of two quadrupole split doublets; only one doublet is observed at room temperature. A direct preparation of $\mathrm{Fe}(\mathrm{py})_{2} \mathrm{Cl}_{2}$ in solution yielded a material exhibiting a single quadrupole doublet at both room temperature and $78 \mathrm{~K}$. The Mössbauer spectral parameters at both these temperatures are essentially the same as those found in the four line spectrum mentioned above. These results were interpreted [1] in terms of a phase transition from a room temperature symmetrically bridged species with a small quadrupole splitting to a low temperature asymmetrically bridged species with a larger quadrupole splitting. The temperature region over which there are four lines in the Mössbauer spec. trum corresponds to the coexistence of the orbital sround states of both of these forms; there is no chıange in spin-multiplicity at any temperature. We illustrate this in fig. 1, where the symmetric structure corresponds to that obtained crystallographically [2] for $\mathrm{Co}(\mathrm{py})_{2} \mathrm{Cl}_{2}$ and the asymmetric structure corresponds to that found [2] for $\mathrm{Cu}(\mathrm{py})_{2} \mathrm{Cl}_{2}$.

In a subsequent study, Sanchez et al. [3] determined the detailed temperature dependence of the Mössbauer spectrum of $\mathrm{Fe}(\mathrm{py})_{2} \mathrm{Cl}_{2}$ prepared in solution. They found that the above mentioned symmetric and asymmetric chloro-bridged forms coexist in the solid state over the temperature range of 235 to $217 \mathrm{~K}$, with the asymmetric species dominating at the lower temperature. A similar phase transition is observed [3] 


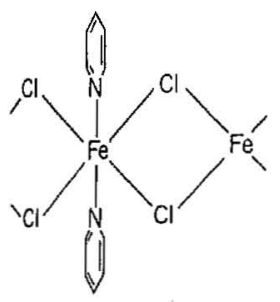

Symmetric Bridging

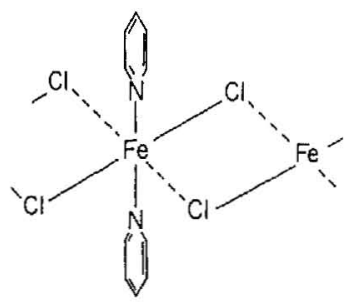

Asymmetric Bridging
Fig. 1. Schematic representations of the symmetric and asymmetric chloro-bridged forms of $\mathrm{Fe}(\mathrm{py})_{2} \mathrm{Cl}_{2}$.

at $\mathrm{ca}, 150 \mathrm{~K}$ in the emission spectrum of ${ }^{57} \mathrm{Co}(\mathrm{py})_{2} \mathrm{Cl}_{2}$. This is the same temperature at which an abrupt clange of sign in the crystal magnetic anisotropy of $\mathrm{Co}(\mathrm{py})_{2} \mathrm{Cl}_{2}$ is observed [4].

In this letter we report the temperature dependence of the Mössbauer spectrum of $\mathrm{Fe}(\mathrm{py})_{2} \mathrm{Cl}_{2}$, measured in a large external magnetic field. We have undertaken this study to better understand the nature of the phase transition and to ascertain whether or not a change in orbital ground state accompanies the structural transformation. The sample of $\mathrm{Fe}(\mathrm{py})_{2} \mathrm{Cl}_{2}$ was prepared in solution by the method A reported previously [1]. The Mössbauer spectra obtained in a zero and a nonzero external magnetic field at room temperature and at $78 \mathrm{~K}$ are presented in figs. 2 and 3 . The Mössbauer isomer shift and quadrupole splitting for the zero field spectra are the same as the values reported previously $[1,3]$. At both high and low temperatures, the Möss* bauer spectrum of $\mathrm{Fe}(\mathrm{py})_{2} \mathrm{Cl}_{2}$ in an external magnetic field exhibits a triplet at negative velocity and a doublet at positive velocity. This implies that the quadrupole coupling constant and hence the principal component of the electric field gradient tensor, is positive [5] at both temperatures. Consequently, the electric field gradient tensor is positive for both the symmetric and asymmetric bridged forms of the complex. The general form of the spectra reflect near axial symmetry [6] (asymmetry parameter, $\eta$, ca. zero) although simulations with small values of $\eta$ were acceptable.

These results may be understood in terms of the relative bonding ability of the four bridging chlorine atoms and two pyridine nitrogen atoms bonded to the central iron(II) ion, and in terms of the local symmetry about the iron. As a ligand, pyridine is much higher in the spectrochemical series than is the chloride

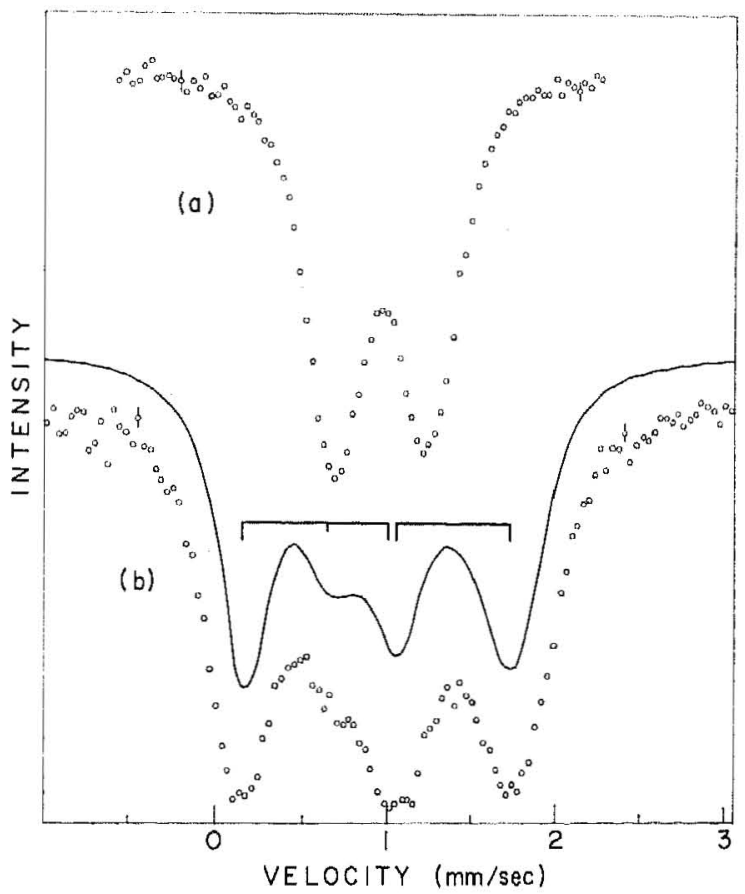

Fig. 2. The Mössbauer spectrum of $\mathrm{Fe}(\mathrm{py})_{2} \mathrm{Cl}_{2}$ at $300 \mathrm{~K}$ with (a) $H=0$, and. (b) $H=45 \mathrm{kG}$. The solid line is a computer simulation with $H=45 \mathrm{kG}, \eta=0$ and $\Delta E_{\mathrm{Q}}=0.53 \mathrm{~mm} / \mathrm{s}$.

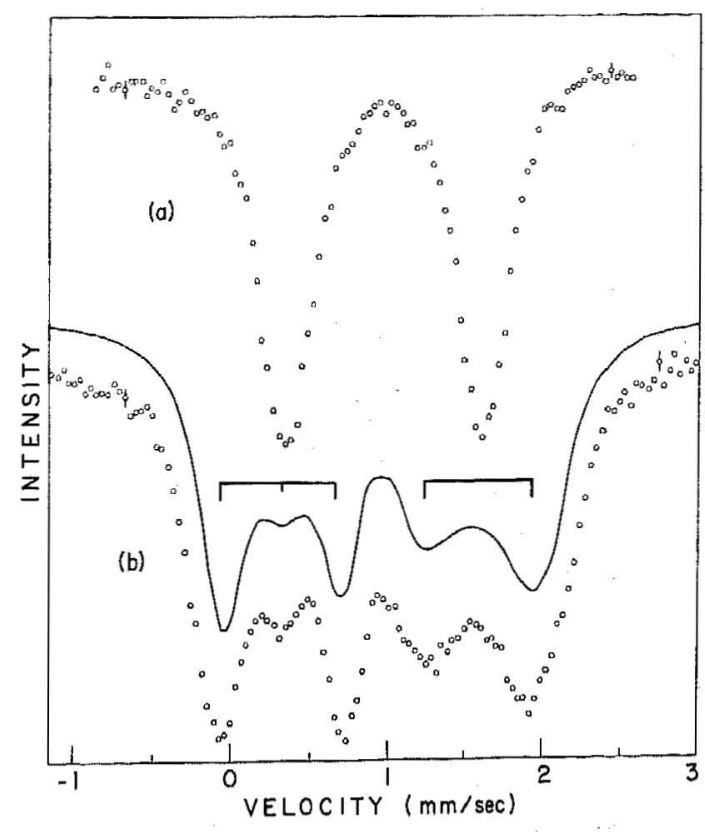

Fig. 3. The Mössbauer spectrum of $\mathrm{Fe}(\mathrm{py})_{2} \mathrm{Cl}_{2}$ at $78 \mathrm{~K}$ with (a) $H=0$, and (b) $H=30 \mathrm{kG}$. The solid line is a computer simulation with $H=30 \mathrm{kG}, \eta=0$, and $\Delta E_{\mathrm{Q}}=1.26 \mathrm{~mm} / \mathrm{s}$. 
fon [7]. Thus it is not surprising that in $\mathrm{Co}(\mathrm{py})_{2} \mathrm{Cl}_{2}$, the cobalt -chlorine distance [2] is $2.49 \AA$ while the cobalt -nitrogen distance is $2.14 \AA$. Similar results are obtained [2] for $\mathrm{Cu}(\mathrm{py})_{2} \mathrm{Cl}_{2}$ in which the copperchlorine distances are 3,05 and $2.28 \AA$ and the coppernitrogen distance is $2.02 \AA$. The room temperature form of $\mathrm{Fe}(\mathrm{py})_{2} \mathrm{Cl}_{2}$ is isomorphous [1] with $\mathrm{Co}(\mathrm{py})_{2} \mathrm{Cl}_{2}$, and it is reasonable to assume shorter iron--nitrogen than iron-chlorine bond lengths in the iron complex. The pyridine ligands in each of these complexes are trans and the angles between the bonds to the metal are all ca. $90^{\circ}$. Thus in $\mathrm{Co}(\mathrm{py})_{2} \mathrm{Cl}_{2}$ and the room temperature form of $\mathrm{Fe}(\mathrm{py})_{2} \mathrm{Cl}_{2}$, the local symmetry of the coordination environment is approximately $D_{4 h}$. From a crystal field point of view, the tetragonal compression of the octahedral ligand field by the trans pyridine ligands destabilizes the $\mathrm{d}_{x z}$ and $\mathrm{d}_{y z}$ orbitals relative to the $\mathrm{d}_{x y}$ orbital, which becomes the ground state orbital. For this ground state orbital, a positive quadrupole coupling constant is expected [6], and is observed for the complex under investigation. If the low temperature form of $\mathrm{Fe}(\mathrm{py})_{2} \mathrm{Cl}_{2}$ is analogous to $\mathrm{Cu}(\mathrm{py})_{2} \mathrm{Cl}_{2}$, in which the copper-chlorine distances are no longer all equivalent, the local symmetry about the metal ion is $\mathrm{D}_{2 \mathrm{~h}}$. However, the complex will still have its strongest ligand field along the pyridine-metal-pyridine axis, and $V_{z z}$, although larger, should still be positive and correspond to a $\mathrm{d}_{x y}$ ground state orbital. Our observation of a positive $V_{z z}$ at both room temperature and $78 \mathrm{~K}$ supports the foregoing analysis.

One can also attempt to analyze the results from a molecular orbital point of view [8]. If differential pibonding effects are more important than sigma-bonding effects, then the $\mathrm{d}_{x z, y z}$ pair can become the ground orbitals. That is, pi donation by the in-plane chloride ions and pi delocalization by the axial pyridine molecules can act in concert to stabilize a ${ }^{5} \mathrm{E}$ ground term composed primarily of $\mathrm{d}_{x z, y z}$ and for which $V_{z z}$ is negative. This does not appear to be the case since $V_{z z}$ is observed to be positive. This approach is one involving separation of sigma- and pi-bonding effects, i.e., the $t_{2 g}$ orbitals are influenced only by differences in pi bonding while the $\mathrm{e}_{\mathrm{g}}$ orbitals are affected only by differences in sigma bonding. Such an approach is valid only in the limit of small distortions from cubic $\left(\mathrm{O}_{\mathrm{h}}\right)$ symmetry [9]. The large splitting [1] (ca. $3900 \mathrm{~cm}^{-1}$ ) of the $\mathrm{e}_{\mathrm{g}}$ orbitals derived from the near infrared and visible spectrum of $\mathrm{Fe}(\mathrm{py})_{2} \mathrm{Cl}_{2}$ suggests that sigma and pi effects are probably not readily separable.

Finally it is also possible that the structure and symmetry of the low temperature form of $\mathrm{Fe}(\mathrm{py})_{2} \mathrm{Cl}_{2}$ are significantly different from that of $\mathrm{Cu}(\mathrm{py})_{2} \mathrm{Cl}_{2}$ such that there is significant mixing of the $\mathrm{t}_{2 \mathrm{~g}}$ and $\mathrm{e}_{\mathrm{g}}$ orbitals components. This would require a different description of the orbital ground state than the simple one we have proposed. However, consideration of such a possibility must await detailed low temperature crystallographic studies of $\mathrm{Fe}(\mathrm{py})_{2} \mathrm{Cl}_{2}$.

On the basis of the nearly two-fold increase in the quadrupole splitting observed for $\mathrm{Fe}(\mathrm{py})_{2} \mathrm{Cl}_{2}$ at $78 \mathrm{~K}$ as compared to room temperature, the change in quadrupole splitting has been interpreted [3] as cor. responding to a transformation from a ground state orbital doublet $\left(\mathrm{d}_{x z}, \mathrm{~d}_{y z}\right)$ at room temperature to a ground state orbital singlet $\left(\mathrm{d}_{x y}\right)$ at low temperature. From a simple crystal field point of view, this is reasonable, because the quadrupole splitting of the doublet is one-half that of the singlet [10]. However, for such a transformation, the sign of $V_{z z}$ should change $[11,12]$, contrary to the results of our work. In addition, there is the inescapable fact that the trans pyridine ligands produce a stronger ligand field and this field would be expected to destabilize the $\mathrm{d}_{x z}$ and $\mathrm{d}_{y z}$ orbitals at all temperatures. Rather than a change in orbital ground state with temperature, the increase in quadrupole splitting with decreasing temperature observed [1] in $\mathrm{Fe}(\mathrm{py})_{2} \mathrm{Cl}_{2}$ seems more compatible with a larger low-symmetry component in the ligand field for the low temperature asymmetric bridged form of the complex, and of the same sign for both forms. In spite of the larger low-symmetry component at low temperature, both forms of the complex have the same orbital singlet ground state $\left(d_{x y}\right)$ and hence, the same sign of $V_{z z}$. It is worthwhile to point out that in an analysis of the low temperature $(9.2 \mathrm{~K})$, magnetically hyperfine split spectrum of $\mathrm{Fe}(\mathrm{py})_{2} \mathrm{Cl}_{2}, \mathrm{~V}_{z z}$ is indicated to be positive [3]. In further support of the foregoing interpretation; the temperature dependence of the magnetic anisotropy for $\mathrm{Co}(\mathrm{py})_{2} \mathrm{Cl}_{2}$ can best be interpreted with one sense (negative) to the tetragonality [4]. This corresponds to a tetragonally compressed octahedral ligand field. The larger low-symmetry ligand field component in the low temperature $\left(D_{2 h}\right)$ form may have as its origin 
an even weaker in-plane bonding relative to the axial bonding when the iron-chlorine bridging bond distances become asymmetric at low temperature. Thus for example the average metal-chlorine distance in $\mathrm{Cu}(\mathrm{py})_{2} \mathrm{Cl}_{2}\left(\mathrm{D}_{2 \mathrm{l}}\right)$ is somewhat longer than the corresponding distance in $\mathrm{Co}(\mathrm{py})_{2} \mathrm{Cl}_{2}$.

The inequivalent iron-chlorine distances in the low temperature form are expected to result in a nonzero asymmetry parameter $\eta$. However, it is difficult to estimate the magnitude of $\eta$ without an elaborate calculation extending beyond the first coordination sphere. As mentioned previously, simulations of the data in fig. 3 were acceptable with non-zero but relatively small values of $\eta(\leqslant 0.4)$. In any event the increase in quadrupole splitting from an increase in $\eta$ to as large as one (which does not occur) can increase the quadrupole effect by only of the order of $10 \%$, much less than the observed increase.

A previous Mössbauer spectral study [3] indicates that the structural transformation involved takes place over a temperature range of about $18 \mathrm{~K}$ for $\mathrm{Fe}(\mathrm{py})_{2} \mathrm{Cl}_{2}$ prepared in solution, and about $3 \mathrm{~K}$ for ${ }^{57} \mathrm{Co}(\mathrm{py})_{2} \mathrm{Cl}_{2}$. As a result, one might consider the transformation to be second order because the transition is not sharp. However, the temperature dependence of both the Mössbauer spectra [3] and the magnetic anisotropy [4] show hysteresis which is more characteristic of a first order than a second order transformation. A more definitive and reliable analysis of the order of this phase transition must await more detailed thermal measurements. A latent heat is expected if the process is indeed first order.
W.M. Reiff is pleased to acknowledge the support of the Research Corporation and the National Science Foundation (Grant Number GH-39010). B.J. Little would like to thank NSF for a Faculty Science Fellowship. G.J. Long would like to thank NSF for Grant Number GP-8653. The Francis Bitter National Magnet Laboratory is supported by the National Science Foundation.

\section{References}

[1] G.J. Long, D.L. Whitney and J.E. Kennedy, Inorg. Chem. 10 (1971) 1406.

[2] J.D. Dunitz, Acta Cryst. 10 (1957) 207.

[3] J.P. Sanchez, L. Asch and J.M. Friedt, Chem. Phys. Letters 18 (1973) 250.

[4] R.B. Bentley, M. Gerloch, J. Lewis and P.N. Quested, J. Chem. Soc. A (1971) 3751.

[5] R.L. Collins, J. Chem. Phys. 42 (1965) 1972.

[6] R.L.Collins and J.C. Travis, Mössbauer Effect Methodology 3 (1967) 123.

[7] F.A.Cotton and G. Wilkinson, Advanced inorganic chemistry, 3rd Ed. (Wiley-Interscience, New York, 1972).

[8] D.S. McClure, Advances in the theory of coordination compounds (Macmillan, New York, 1961) p. 498.

[9] A.P.B. Lever, Inorganic electronic spectroscopy (Elsevier, Amsterdam, 1968) p. 205.

[10] R. Ingalls, Phys, Rev. A133 (1964) 787.

[11] W.M. Reiff, R.B. Frankel and C.R. Abeledo, Chem. Phys. Letters 22 (1973) 124.

[12] R. Latorre, C.R. Abeledo, R.B. Frankel, J.A. Costamagna, W.M. Reiff and E. Frank, J. Chem. Phys. 59 (1973) 2580. 